\title{
MEMÓRIA, EMOÇÃO, COGNIÇÃO NOS CANTOS IRADE DOS AYORÉ DO CHACO BOREAL
}

Jean-Pierre Estival

Por que cantar mais que contar? Como dar conta da potência emotiva que suscitam as canções - e particularmente as canções de amor — em muitas culturas humanas? Estes temas — tão vastos para a etnomusicologia do particular que nos interessa, tão pregnantes em nossas pesquisas de campo para que sejam esquecidos - serão aqui muito modestamente tangenciados, evocando a organização dos conhecimentos em uma sociedade do Chaco, de um ponto de vista antropológico, ainda que iluminado pelas ciências cognitivas.

A cultura e a sociedade dos Ayoré é uma das mais bem-estudadas do Chaco: de fato, esta sociedade tão original suscitou numerosas vocações etnográficas, mesmo que se possa considerá-la marginal em relação ao paradigma "chaqueano" introduzido por Métraux 1996 [1946], paradigma que permanece amplamente válido para a cultura clássica dos vizinhos ${ }^{1}$ dos Ayoré. De um grande número de pesquisas, citaremos em particular os trabalhos de Bartolomé (2000), Bernand-Muñoz (1977), Bórmida (1973, 1974, 1975, 1976), Bórmida e Califano (2003 [1978]), Casalegno (2003 [1985]), Fischermann (1988, 2005), Mashnshnek (1988-89), Sebag (1965), e as compilações de Amarilla Stanley (2001) e Zanardini (2003). Encontramse nesses trabalhos numerosas informações etnográficas sobre os mundos sonoros ayoréo que foram sintetizadas em Estival (2005). Sobre os cantos, dispomos ainda da pequena obra de Riester \& Zolezzi (1985), que apresenta textos (em ayoré e espanhol), assim como uma breve análise musical.

\section{Os cantos irade}

No seio dos diversos grupos Ayoré, apenas um tipo de canto resistiu nitidamente ao contato com a sociedade neo-americana: os cantos irade. Eles não apenas são praticados constantemente, como dão lugar ainda a criações 
no seio do gênero, o que comprova uma segura vitalidade da tradição. No entanto, na civilização ayoréo de antes do contato, conheciam-se outras formas cantadas, em particular as fórmulas de cura xamânica (curativas e propiciatórias) de cantos executados por ocasião de rituais coletivos, às vezes nos relatos míticos (Estival 2005). Hoje em dia, os grupos Ayoréo contatados ${ }^{2}$ vivem na sociedade neo-americana e, em sua imensa maioria, passaram de uma economia de caça e coleta a uma de trabalhadores agrícolas precários ${ }^{3}$, ou de coletores de iscas para a pesca esportiva dos turistas brasileiros. ${ }^{4}$

Apesar da pressão missionária evangélica, não é raro que, ao cair da noite, uma grande parte da comunidade se junte ao redor de uma fogueira a fim de escutar os cantores jnecatai com seu pakã (chocalho) e as cantoras jnecate. Eis um exemplo resumido de meu caderno de campo: ${ }^{5}$

Comunidade de Isla Alta, 11 de outubro de 1997, 20h: Os Ayoré se reúnem pouco a pouco diante da casa de Usigai, trazendo suas caças e formando um círculo em torno do fogo, cujos reflexos ondulantes iluminam os rostos. As crianças brincam, perseguindo-se no labirinto formado pelos adultos sentados. Fala-se, e o barulho de abanadores açoitando as costas para afastar — sem real eficácia — os mosquitos pontua as conversas e os risos. O primeiro cantor avança para o centro, concentrase e começa a respirar cada vez mais forte. Ele se apóia sobre seu bastão, inclina-se ligeiramente, detém-se olhando o céu e assoprando, e logo começa a entoar seu canto. A voz é marcada por um impressionante vibrato, a amplitude é restrita, mas o que mais impressiona é, sem dúvida, a forte investida do cantor: sua melodia, sustentada pelo som arredondado do chocalho, é tensa e pontuada por ruidosas expirações a cada fim de frase. O corpo está curvado sobre o bastão, por vezes treme, e mesmo se a fraca luz do fogo não me permite seguir constantemente o rosto do cantor, sua expressão e seus olhos semicerrados deixam transparecer o que me parece ser uma intensa emoção. A audiência, por sua vez, escuta com atenção, à exceção das crianças que continuam suas brincadeiras, agora mais silenciosas. O terere ${ }^{6}$ circula, e ouvem-se muito freqüentemente breves conversas em voz bem baixa que, assim como o barulho dos estalos dos abanadores, tampouco perturbam a concentração manifesta de muitos espectadores. Ao fim do trecho, após ter repetido seu sopro, o cantor responde a alguns rápidos comentários que lhe são feitos pelos membros da audiência. Em seguida, ele vai se sentar com os outros e, quase imediatamente, Gusua, uma mulher idosa, chega com sua caça e se posta na primeira fila para cantar. Ela não porta chocalho nem bastão, e ainda que sua voz seja mais fraca, ela canta com as mesmas características estilísticas aparentes que as de seu predecessor: vibrato, fortes expirações ao fim de cada frase. Também ela se detém às vezes, recobra a respiração, faz alguns breves comentários falados antes de prosseguir com seu canto. 
Os irade apresentam várias características que os opõem às fórmulas terapêuticas ou propiciatórias (sahode, eraí, paragapidí, aguyáde) e às recitações míticas, que qualificaremos na próxima seção.

A mais fundamental pode ser assim enunciada:

Os irade contam histórias em que os humanos se dirigem aos humanos ou, dito de outra forma, em que a referência à história eventual do grupo é central. Seguramente para os Ayoré, o jahogue (tamanduá) e os nanibahade (ancestrais míticos) também podem se dirigir aos humanos, e reciprocamente. Mas isso eles não farão jamais no contexto dos irade.

Os cantos irade mais correntes são cantos de amor triste, os jnusietigade: eles podem ser cantados pelos homens ou pelas mulheres, e contam as dificuldades da vida amorosa cotidiana, sempre de modo narrativo.

A seguir, vêm os relatos de guerra pocaningane: ainda com um modo narrativo, eles tratam de histórias de guerras passadas, valorizando, por vezes não sem ironia, a valentia (dicase: valente) dos dacasute (guerreiros eméritos que já mataram homens ou jaguares).

Enfim, os relatos de visões de xamãs enominone. Ainda que associados ao xamanismo, esses não são, de forma alguma, cantos curativos ou propiciatórios, como os sahode. Os enominone também contam histórias reais, nas quais o naijnai (xamã) usa seus poderes de visão ou de transformação para alcançar seus fins no domínio da guerra, da caça ou, de forma mais geral, na vida do grupo.

Essas temáticas diferentes são executadas exatamente com a mesma forma: as mulheres à capela, e os homens acompanhando-se com o chocalho pakã. Em um artigo de introdução aos mundos sonoros ayoréo (Estival 2005), eu publiquei uma quinzena de textos de cantos (ayoréo/espanhol). Eis um exemplo de um enominone:

1. - Garidi ama je yo narijna, yo narijajni yu durasede ga,

— Disse a Garidi: tornei-me xamã, xamã, na noite passada,

2. - Yajire que yajire que yajire cucha darade manengungurinie durasede mu, yocajnenie cope noñaguei (g)bajnai gadoi,

- Vi, vi, vi durante minha visão que vinham até nós colares de plumas decompostas,

3. - Ti ga Garidi Ijnapuigosode ore garidi ngajnine ga yocajnai cope noñague dipesei jnai,

— Disse outra vez a Garidi: esses colares decompostos que eu vi significam que os Ijnapuigosode ${ }^{7}$ virão nos atacar,

4. - Urate que yireque yireque ore ijnapui gosode ore,

- O exemplo do colar decomposto tem um sentido muito ruim, o que vai ocorrer a eles com a chegada dos Ijnapuigosode, 
5. - Ijnapui gosicaisode a ore añarachaque monganguejnane,

- As armas que os Ijnapuigosode possuem não vão perdoar ninguém, pois são muito perigosas.

6. - Ga chi Garide chi Ijnapuigosode ore pero yioquibai niome niome,

— Disse outra vez a Garidi: os Ijnapuigosode virão todos em cima de nós amanhã, amanhã,

7. - Ga chi jnuquenejnai uñeque ga chi ingajno ngoraque ingajno ngoraque, queseite ga mongajna que yieque mongaringueique,

- Participará do ataque Jnuquenejnai, e virá com sua lança que ninguém consegue vencer,

8. - Garidia yojaque narijna narijna iji yu que ga,

— Disse outra vez a Garidi: tentei ser xamã, xamã, durante minha visão,

9. - Yojoque yadome, yoque ga ijnapuri gosicaisode ore añuadate mongajnaqueode,

- Durante minha visão, procurei lutar contra as armas dos Ijnapuigosode, demasiado perigosas que eles têm,

10. - Nui que yijuime ari que que.

- Mas não pude evitá-las.

Aos irade está associada uma grande eficácia em dois registros emotivos igualmente valorizados: o campo amoroso — como em toda parte - e a noção de valentia particularmente cultivada por esta sociedade. $\mathrm{O}$ aspecto muito presente da vida amorosa já havia sido notado por Carmen Bernard, logo após a publicação de 20 resumos de textos de cantos coletados por Sebag: "Como em todas as sociedades, os homens e as mulheres dão livre curso aos seus desejos, cantam seus amores contrariados, exprimem seu ciúme e seu desespero" (Bernard-Muñoz 1977:92-93).

Esses registros emocionais são sempre referentes às dimensões históricas da memória dos indivíduos: os fatos evocados (amores, guerras e outros) são inscritos na memória de longo prazo de muitos ouvintes Ayoré, e tentaremos mostrar mais adiante que o fato de essas histórias serem cantadas pode ter uma influência eficaz nos processos de inscrição mnésica. De um ponto de vista antropológico, as histórias indicam dois campos - o casamento e os inimigos — que a etnologia americanista recente por vezes considera como declinações da afinidade.

No nível da performance, a voz tensa, caracterizada por um amplo vibrato, e a capacidade de colocar muita energia no sopro participam da noção de valentia, verdadeiro ideal do ethos ayoréo. O sonograma da Figura 1 (a $4000 \mathrm{~Hz}$ ) mostra claramente a importante amplitude do vibrato ayoréo: pouco após o início do canto, ele atinge quase uma sétima menor, o que é excepcional. Na primeira parte da frase, vai-se de $175 \mathrm{~Hz}$ (Fá $2+4$ cts) a 


\section{Figura 1}

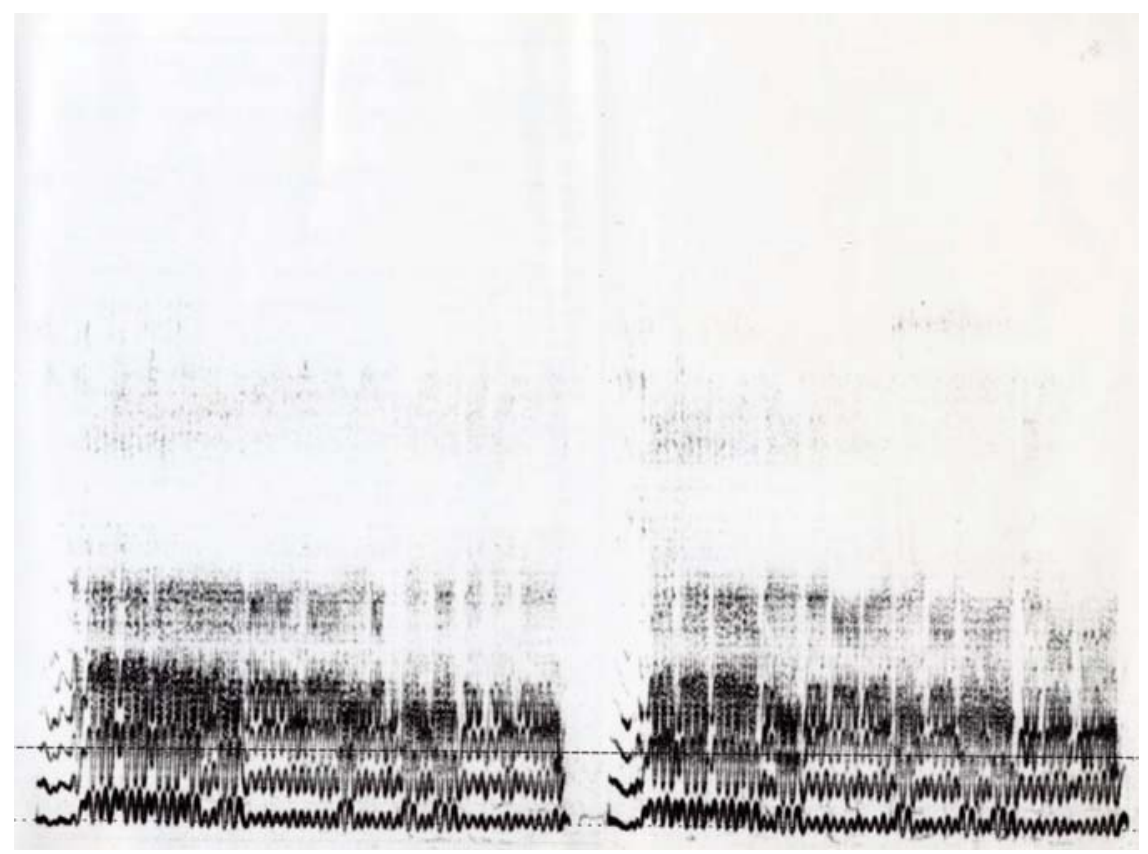

$325 \mathrm{~Hz}$ (Mi 3 - 24 cts). Na segunda parte, de modo mais restrito, vai-se de $160 \mathrm{~Hz}$ (Ré \# $2+49$ cts) a $240 \mathrm{~Hz}$ (Si $2-49$ cts), ou seja, mais de uma quinta. Pode-se escutar esse canto na página 16 de Estival (2002).

Os textos dos cantos são muito difíceis de serem compreendidos devido ao tipo de voz cantada, mas também ao caráter alusivo das palavras, que demanda esforço de memória para bem entender a história narrada. Veremos que esse empenho poderia, pela atenção que mobiliza, participar dos esforços de inscrição na memória de longo prazo dos indivíduos afetados pelos cantos.

As histórias de amor são em geral dolorosas e conflituosas para seus protagonistas, e o fato de que uma terceira pessoa as cante permite certa catarse. Sua exposição pública, fazendo-as entrar na memória coletiva, contribui, por um lado, para moderar as fofocas e, por outro, para relativizar os potenciais conflitos entre grupos de parentesco.

Os relatos de guerra possuem um caráter de epopéia ${ }^{8}$, valorizando a valentia dos dacasute (grandes guerreiros), mas por vezes não sem ironia.

A dramatização da expressão cantada, veremos adiante, poderia contribuir nos processos de rememoração, participando assim do reforço da unidade social do grupo local, seja para a neutralização dos conflitos internos (jnusieti- 
gade), seja para a exaltação dos conflitos externos (pocaningane). Esta é a expressão vocal dos cantos irade que os Ayoréo escolheram prioritariamente.

\section{As fórmulas e outros cantos}

Veremos agora que outras fórmulas - para muitos em forte declínio na sociedade contemporânea - existem (existiam) também entre os Ayoré. Atualmente é extremamente difícil, ao menos para um observador externo, testemunhar sobre essas formas: os rituais xamânicos, tais quais descritos por Sebag (1965), não parecem mais (ou são muito pouco) praticados, como também o uso das fórmulas sahode para fins curativos ou propiciatórios. ${ }^{9}$

No seio dos cantos, relatos e salmodias ayoréo, as fórmulas constituem um conjunto que se pode desmembrar, segundo Mashnshnek (1988-89:43), em subseções: sahode: fórmulas curativas ou propiciatórias; erái: cantos propiciatórios no domínio específico da caça e da colheita; paragapidí: fórmulas de proteção contra um mal particular ${ }^{10}$; aguyáde: cantos específicos contra as pragas nas roças.

O autor assim caracteriza tal conjunto:

Estes cantos são a manifestação concreta da presença e do poder dos antepassados nanibahade. Os sahode, erái, paragapidï têm em comum sua estreita relação com os mitos: não são os homens que pronunciam as poderosas palavras, mas os próprios seres míticos (Mashnshnek 1988-89:43).*

As fórmulas são, pois, as palavras dos ancestrais míticos nanibahade; elas são transmitidas desde o tempo em que a diferença interespecífica homens/animais não era efetiva, e na qual eles formavam uma humanidade comum (Sebag 1965:92-93; Bórmida e Califano 2003 [1978]:173,184; Casalegno 2003 [1985]:434). No âmbito temporal, existe uma diferença fundamental entre os irade, que contam uma história passada, e as fórmulas que agem no presente ou no futuro a curto ou médio prazo.

Por exemplo, podemos ver que a fórmula sahode seguinte ${ }^{11}$, utilizada para acalmar a chuva e defender-se dos relâmpagos, é uma imprecação que não conta de forma alguma uma história vivida por humanos:

* [N. T.]: traduzido a partir da citação original em espanhol: “Estes cantos son la manifestación concreta de la presencia y del poder de los antepasados nanibahade. Los sahode, erái, paragapidï tienen en comun su estrecha relación con los mitos: no son los hombres que pronucián las poderosas palavras, si no los proprios seres míticos". 


\author{
Yajogue ujñarone (sahode do filho do tamanduá) \\ Serei poderosa! \\ Destruirei os que me odeiam! \\ Destruirei os que me odeiam! \\ Destruirei os que me odeiam! \\ Direi novamente \\ Serei poderosa, serei poderosa, serei poderosa \\ Minha grande fórmula destruirá tua grande fórmula \\ Hoje acalmará (cospe) \\ (citado em Zolezzi e Riester 1985:35)
}

As palavras, carregadas de potência, são antes de tudo pronunciadas segundo um modo por vezes salmódico, mas discreto, com o objetivo de eficácia prática: trata-se de agir sobre a chuva e os relâmpagos. Sebag (1965:96) notava justamente que as frases das fórmulas são sempre construídas em primeira pessoa e, sendo assim, não são entidades evocadas, mas entidades que agem quando querem; dessa forma, o caráter eminentemente performativo desses sahode constitui sua essência. Sua potência faz com que as palavras não possam ser proferidas de forma livre, permanente ou fora de propósito, pois em caso contrário elas se tornam extremamente perigosas, trazendo um risco mortal para aquele que as pronuncia (Sebag 1965:95). Esta noção de condições restritivas de enunciação ou de expressão é exprimida pelos Ayoré pelo termo genérico puyak (freqüentemente traduzido, de modo bastante aproximado, por interdito ou tabu).

Se as fórmulas são carregadas de potência, sua enunciação tem, no entanto, volume muito baixo. No ritual xamânico de cura, elas são pronunciadas em voz baixa, quase em contato com o corpo do doente (Bórmida e Califano 2003 [1978]:173). Sebag (1965:7-8) descreve a execução de um canto que começa bem baixo, cujo volume aumenta, mas que é sobretudo entrecortado por momentos de inalação de tabaco.

Quanto à performance, um ponto interessante é o do sopro. No caso dos irade, foi visto que a forte respiração do cantor era de algum modo projetada à boa distância ao conjunto das pessoas. Para as fórmulas curativas, o sopro é orientado, dirigido; é diretamente a potência do nanibahade que passa ao corpo do paciente. O próprio termo sahode pode, aliás, ser substituído para uso terapêutico por cuvucu", "eu assopro" (Bórmida e Califano 2003 [1978]:173).

As cuchade adode - narrações de coisas passadas - tanto quanto os cuchade quique ujaidie - mitos do início e origem das coisas (Barrios et alii 1995:31) — são relatos por vezes e em parte salmodiados. Ainda que sua vocação seja também, como o é para os irade, inscrever-se na memória 
coletiva (Bartolomé 2000:51-56), eles não podem, em geral (contrariamente aos irade), ser enunciados publicamente de forma completa. Numerosas partes, relatando a potência da palavra dos nanibahade, estão de fato carregadas de poder e de puyak.

Enfim, os Ayoré interpretavam em público os cantos individuais ugaijnane no grande ritual de Asojna (Fischermann 2005:428); mas estes eram todos sem palavras, distinguindo-se, de modo radical, dos irade, nos quais o caráter narrativo é primordial.

Para resumir, apresentamos o seguinte quadro:

\begin{tabular}{|l|l|}
\hline Irade & sahode, erái, paragapidí \\
\hline $\begin{array}{l}\text { O canto é um relato que se refere a } \\
\text { eventos identificáveis associados à } \\
\text { memória histórica coletiva (amores, } \\
\text { guerras, viagens de xamãs). }\end{array}$ & $\begin{array}{l}\text { Os cantos — recitações - referem-se ao } \\
\text { tempo mítico dos nanibahade, ances- } \\
\text { trais da época em que os seres da "na- } \\
\text { tureza" não eram distintos dos Ayoré. }\end{array}$ \\
\hline $\begin{array}{l}\text { A cantora ou o cantor canta o canto de } \\
\text { um indívíduo particular, em geral outro } \\
\text { que não ela/ele mesma/o, sem efeito } \\
\text { terapêutico ou propiciatório. }\end{array}$ & $\begin{array}{l}\text { O especialista igasitái pronuncia a de um nanibahade dotado } \\
\text { de poderes terapêuticos ou propicia- } \\
\text { tórios. }\end{array}$ \\
\hline $\begin{array}{l}\text { A performance é pública, a cantora } \\
\text { ou o cantor expõe sua emoção e sua } \\
\text { valentia, manifestas pela potência de } \\
\text { seu canto. }\end{array}$ & $\begin{array}{l}\text { A performance é cercada de numerosos } \\
\text { puyak (interditos), e a potência e a eficá- } \\
\text { cia da fórmula não dependem da intensi- } \\
\text { dade sonora, que é geralmente fraca. }\end{array}$ \\
\hline
\end{tabular}

\section{Perspectivismo e cognição}

Iremos examinar rapidamente algumas pistas determinantes de ligações entre propriedades cognitivas gerais do canto (de um ponto de vista psicológico) e algumas características antropológicas e cognitivas do pensamento ameríndio.

Comecemos por estes últimos, em vista dos conhecimentos atuais. Em um texto essencial para muitos americanistas das Terras Baixas, Eduardo Viveiros de Castro (2002:349) propunha a seguinte fórmula: enquanto o multiculturalismo moderno se sustenta sobre a unidade da natureza e a multiplicidade das culturas - a primeira garantida pela universalidade objetiva dos corpos e da substância, a segunda gerada pela particularidade subjetiva 
dos espíritos e do sentido - a concepção ameríndia suporia, ao contrário, uma unidade do espírito e uma diversidade dos corpos.

Ainda que o próprio autor considere a fórmula talvez excessivamente simétrica para ser mais que especulativa, ela parece ter para o Chaco grande pertinência (Ayoré e sobretudo Ñandeva). Assim, os animais ou os ancestrais nanibahade vêem e pensam como os humanos - por exemplo, os animais predadores e os espíritos malignos vêem os humanos como caça, enquanto vêem a si mesmos como humanos. Seus cantos, fórmulas e mitos dirigem-se a um espaço social onde eles agem sobre os Ayoré atuais, seja para guerrear com eles, seja para lhes causar dano ou para influir sobre seu futuro. Tais ações são produzidas por cantos ou recitações (às vezes um ou outro: fórmulas curativas e propiciatórias, os mitos) enunciadas de forma não-pública e, como já visto, cercadas de interditos (puyak). Elas se inscrevem em uma moldura perspectivista clássica, na qual as mediações entre os seres dependem de práticas xamânicas. Os seres vivos pertencem a classes diferentes, mesmo se seu quadro referencial comum é a cultura e a sociedade, e não a noção ocidental de natureza. Os sahode, em particular, dependem de mediações interclasses - por exemplo, os nanibahade ou os animais quando ainda eram humanos - nas quais o naijnai é o mediador.

A capacidade de cantar, segundo o modo característico dos irade, depende de um outro espaço, público, onde os humanos dirigem-se aos humanos. Isso se passa no seio de uma mesma classe de ser vivo. Ainda que a pesquisa não tenha sido muito clara a esse respeito, parece que no seio de uma mesma classe diversa da humana (como os catai — jaguares — entre eles) pratica-se também os irade: quadro perspectivista segundo o Erklärung das categorias cognitivas ameríndias propostas por Viveiros de Castro.

Por que cantar então, quando os Ayoré possuem também uma forma de monólogo que encena suas façanhas guerreiras? ${ }^{13}$ Sem dúvida, porque o fato de cantar tem propriedades de inscrição cognitiva que fazem os irade particularmente eficazes em sua função dentro do grupo.

\section{A frágil potência da memória ${ }^{14}$}

Os cantos irade apontam, pois, entre os cantores, assim como entre os ouvintes, para processos e emoções que são ligados às questões de memória.

Se a arquitetura geral da memória humana é ainda sujeita à discussão, tanto teórica quanto terminológica, nós nos interessaremos, em relação aos cantos irade, pela memória explícita de longo prazo, ou seja, aquela que concerne a eventos ou a conceitos verbalizáveis. ${ }^{15}$ 
Subdividindo um pouco mais, podemos aqui considerar que os cantos irade se referem à memória episódica dos indivíduos que estiveram associados de modo direto aos eventos narrados nos cantos. Para os demais sujeitos, que não tiveram a experiência sensível de tais eventos, os cantos têm uma função de aprendizagem dos eventos no correr de sessões noturnas. Trata-se para nós agora de tentar qualificar algumas das características desses processos mnésicos, e assim mostrar sua eficácia. Vejamos o que dizem as ciências cognitivas e, em particular, a neuropsicologia: entre as ciências cognitivas da música, esta é sem dúvida a que apresenta resultados os mais evocáveis em antropologia. Ao se descreverem fatos biológicos próprios ao cérebro humano, pode-se, ainda que com prudência, tentar inferir hipóteses a partir de certos resultados.

Os trabalhos sobre a memória humana constituem um domínio imenso (Baddeley 1993 [1990]; Schacter 1999 [1996]; Squire \& Kandel 2002 [1999] para o estado da arte deste campo), enquanto a memória musical foi, até o presente, menos explorada (como mostra a introdução de Snyder 2000), tanto por experimentações clássicas quanto por técnicas de magneto-encefalografia ou por imagens de ressonância magnética funcional (Platel 2004:45, 54). Eis por que ficaremos com hipóteses gerais.

Desde Tulving e Thomson (1973), sabemos que os processos de codificação de um evento não são context free, mas context dependant. Esta hipótese, avançada já em 1690 por Locke (Baddeley 1993:289), foi mostrada por diversos trabalhos experimentais (Baddeley 1993:289-96), como resume Schacter:

[...] o modo específico pelo qual um sujeito trata ou codifica um evento determina aquilo que "penetra" no engrama ${ }^{16}$, e a probabilidade de lembrança ulterior do evento depende do modo pelo qual um indício de lembrança reinstala a codificação original ou se conjuga com ela. A recordação explícita depende sempre da similaridade ou da afinidade entre os processos de codificação e de recuperação (Schacter 1999:78).

No modo como nos recordamos dos eventos ou dos conceitos, há um efeito de contexto que concerne particularmente aos irade - mas também aos cantos, de forma mais ampla: é a emoção que eles produzem.

\section{Memória, emoção, irade}

É de uma grande banalidade afirmar que as canções ocupam um primeiro plano nas práticas ou nas consumações culturais de muitas culturas humanas. Esta é, em todo caso, uma verdade para os Ayoré, os brasileiros ou 
os franceses... Não é aqui o lugar de entabular um debate tão amplo, mas lembremos que em nossas culturas é ao menos bastante freqüente a emoção ligada à produção de uma lembrança ou de uma deliciosa nostalgia do passado que suscita o interesse por esta ou aquela canção.

Iremos, pois, procurar investigar os laços entre memória, emoção e canção, na tentativa de aplicar alguns resultados aos irade.

De um modo geral, as ciências cognitivas mostraram que a exatidão da lembrança está, com freqüência, diretamente ligada à emoção suscitada por uma experiência, seja ela positiva ou negativa (Schacter 1999:248). De um ponto de vista neurofisiológico, parece atualmente aceito que:

Se a amídala e o sistema hipocâmpico subentendem respectivamente (e independentemente) as lembranças emocionais não-declarativas e as lembranças declarativas ${ }^{17}$, os dois sistemas podem cooperar. Por exemplo, as pessoas se lembram particularmente bem de eventos com forte conteúdo emocional. Em laboratório, a memória declarativa para material carregado emocionalmente é, praticamente sempre, de melhor qualidade que a memória para material neutro. Esta capacidade da emoção de melhorar a memória declarativa depende da amídala (Squire \& Kandel 2002:211).

Vimos que os irade provocavam, tanto entre os cantores quanto entre os ouvintes, um alto nível emocional. Este nível emocional é induzido pela produção sonora, mas também pelo conjunto do fato social que constitui uma sessão noturna de canto.

Por um lado, os cantores ou as cantoras provêm - nos casos observados - da comunidade. Mesmo se o canto é encenado, não se trata para os ouvintes de escutar um artista vindo de alhures, mas sim um dos seus que vai cantar histórias que dizem respeito a todos.

Por outro lado, a performance dos cantos implica uma encenação particular do corpo: fortes e ruidosas inspirações e expirações no início - e depois, ao fim de cada frase - que além de seu papel fisiológico de ventilação necessária ao esforço do intérprete têm o papel de marcar seqüências do canto. Estes momentos de potente sopro permitem também ao ouvinte integrar o que acaba de ser cantado e renovar a sua atenção.

A fraca, cambiante luz do fogo permite à audiência perceber os movimentos gerais do corpo do cantor ou da cantora, e quando a resina da $a c a i^{18} \mathrm{se}$ inflama, as expressões, a emoção do artista são como que reveladas em uma breve seqüência. Este fugaz desvelamento do rosto e do corpo, combinado ao delicioso odor da resina, constitui um momento em que os espectadores ${ }^{19}$ congelam por alguns instantes, interrompendo, inclusive, o balé dos caçamosquitos. Isto permite aos ouvintes ver e imaginar os gestos do cantor, 
apreciar sua emoção e apropriar-se dela em uma atmosfera emprestada.

Vejamos em que esse contexto da performance pode auxiliar a rememoração. Segundo Bower (1981), os sentimentos emocionais são indícios de recuperação de lembranças. Assim, as canções associadas a respostas emocionais deveriam ser melhor recordadas e engendrar mais lembranças do que canções desprovidas deste tipo de respostas, ou caracterizadas por respostas emocionais moderadas.

\section{Uma especificidade mnésica das canções?}

Comecemos por uma constatação: "A precisão com a qual nos lembramos de certas canções é muito surpreendente, e pode conduzir a interrogar-nos sobre os processos cognitivos e as estruturas cerebrais implicadas nestes mecanismos mnésicos" (Platel 2004:35).

De um modo geral, a coexistência na canção de estímulos musicais e verbais parece favorecer uma inscrição mnésica durável. É mesmo próprio dos cantos associarem estes dois tipos de estímulos. As simples melodias não vinculadas a um conteúdo semântico explícito têm uma inscrição mnésica que concerne mais especificamente ao lobo temporal direito (Samson e Zatorre 1991; Platel 2004).

O conjunto dos resultados concernentes à percepção das canções mostra a influência das palavras de uma canção sobre a retenção da melodia, e permite pensar que existe um sistema especializado na memória das canções que se distingue do sistema de memória melódica e do sistema de memória verbal (Platel 2004:35).

Podemos, pois, exprimir a hipótese de que, na estruturação de seus conhecimentos, o uso dos repertórios cantados de humano para humano permite aos Ayoré reforçarem inscrições mnésicas partilhadas no seio de um grupo local. A emoção suscitada pelos irade participaria desse reforço.

Podemos também emitir uma hipótese sobre as razões que levaram os Ayoré a praticarem esses cantos irade. A primeira seria de ordem sociológica. A sociedade ayoréo é muito complexa, pois um indivíduo lambda pertence ao mesmo tempo a um grupo exogâmico de descendência patrilinear sem localização territorial - cucherai - e também a uma família extensa - jogasui - reagrupada com outra em um grupo local territorial, por exemplo, guidaigosode, gente das aldeias. Assim, o indivíduo lambda pode ser picanerai (um dos sete cucherai) e guidaigosode. Por ocasião de conflitos intertribais, as solidariedades eram territoriais (é possível citar os conflitos clássicos entre guidaigosode e totobiegosode), ainda que a situação na qual 
um picanerai devesse matar um outro picanerai tendesse a ser evitada na medida do possível (informações dadas por Oojoi de Isla Alta, mas também presente nas referências citadas).

Em uma sociedade que pratica (ou praticava) com entusiasmo tanto a guerra intratribal quanto a extratribal, a constituição de uma "memória coletiva", centrada nos fatos internos (jnusietigade, enominone) e externos (pocaningane, enominone) ao grupo local, permite evidentemente consolidar os laços sociais para o reforço dos conteúdos mnésicos partilhados.

Para terminar, um ponto que gostaríamos de evocar rapidamente: no âmbito de nossa cultura ocidental, mostrou-se (Schacter 1999; Kemper et alii 1990; Pratt \& Robins 1991) que os sujeitos idosos possuíam maiores aptidões para contar histórias. Isto foi, sem dúvida, bem constatado empiricamente e de forma freqüente em sociedades de tradição oral, mas pode-se dizer que entre os Ayoré este fato é confirmado: a maioria dos cantores ou cantoras é bastante idosa. ${ }^{20}$ De resto, no que concerne à composição dos cantos, Bórmida indica que: "Uma atividade própria dos anciãos de ambos os sexos é compor e cantar loas aos guerreiros, pelas quais recebem uma compensação" (Bórmida e Califano 2003 [1978]:157).*

As fórmulas com finalidade curativa ou propiciatória, às vezes cantadas, como os sahode, não se baseiam na mesma lógica cognitiva: elas não são públicas, são perigosas, e não têm vocação de se inscreverem na memória de todos, muito pelo contrário, não se saberia proferi-las sem múltiplas precauções, e somente especialistas podem domesticar-lhe a potência. Cantos de ancestrais, cantos de espíritos situam-se em outra perspectiva.

Os Ayoré podem, entre eles, graças aos irade, partilhar uma memória para reforçar os laços no seio do grupo local. Os nanibahade agem por meio de suas fórmulas, com discrição e potência, em um campo totalmente outro, que não envolve as mesmas questões de memorização partilhada.

Recebido em 29 de agosto de 2005

Aprovado em 09 de fevereiro de 2006

Tradução de Flávio Gordon

Jean-Pierre Estival é membro do Laboratoire d'Ethnomusicologie do CNRS, Paris.

E-mail: <jphenryestival@yahoo.com>

\footnotetext{
* [N. T.]: traduzido a partir da citação original em espanhol: “Una actividad propria de los ancianos de ambos sexos es el componer y cantar alabanzas para los guerreros, por lo cual recibe una compensación".
} 


\section{Notas}

${ }^{1}$ Pensamos em particular, no nível musical, nos Guarani-ñandeva (Tapietés), Manjui (Choroti), Nivacle (Chulupi), Enthlet (Lengua), Enenthlet (Toba-Maskoy).

${ }^{2}$ Há ainda alguns pequenos grupos não-contatados de Ayoréo totobiegosode, cujos territórios são gravemente ameaçados (maio de 2005) por invasões latifundiárias paraguaias e brasileiras.

${ }^{3}$ No Chaco central, sob dominação econômica menonita.

${ }^{4}$ Sobre o rio Paraguai, em frente a Porto Murtinho (MS).

${ }^{5}$ Eu trabalhei entre os Ayoré nas comunidades de Isla Alta (1997-98) e Arocojnadi (2003), assim como em meio urbano, junto a pessoas idosas em tratamento (Filadelfia, Asunción), entre 1997 e 2004.

${ }^{6}$ Decocção de yerba maté fria, característica da convivialidade paraguaia, e adotada com entusiasmo por todos os ameríndios do Chaco.

${ }^{7}$ Gênero das palmeiras carandá (copernica alba; família: arecaceae). Baseado em Schmeda Hirschmann (2003).

${ }^{8}$ Não podemos deixar passar em branco, ao utilizar esse termo, as questões colocadas por Pascal Boyer (1988). Os irade funcionam, no entanto, sob um registro outro que o mvët. Para aquilo que toca a reflexão geral sobre as características da tradição, nós nos referiremos em particular ao capítulo IX (Boyer 1988:165-184).

${ }^{9}$ Seguramente, é preciso ser prudente sobre o "desaparecimento observado" de tal ou qual forma ou prática cultural; entre os Ñandeva, vizinhos dos Ayoré, observamos em 2002 a reatualização enérgica de um grande ritual "desaparecido" há aproximadamente 50 anos.

${ }^{10}$ D'Onofrio (2003:64-66) dá o exemplo do paragadí como ritual de purificação após uma morte.

${ }^{11}$ A fórmula é dada em versão bilíngüe na obra citada.

${ }^{12}$ Mais seguramente chuvuchu, como é notado também por Schmeda Hirschmann (2003:520).

${ }^{13}$ A bem da verdade, raramente executada em nossos dias.

${ }^{14}$ Esta bela fórmula é freqüentemente empregada por Schacter (1999). 
${ }^{15}$ Por contraste, à memória implícita concernem atos motores, como tocar violão ou atirar com arco.

${ }^{16}$ Uma definição: "O engrama constitui um conjunto de modificações transitórias ou duráveis de nosso cérebro que resultam da codificação de uma experiência" (baseado em Schacter 1999:76). Ver também Squire \& Kandel 2002:91. N. T.: A palavra engrama existe em português, sendo um termo técnico usado nas neurociências.

${ }^{17} \mathrm{Ou}$ seja, a memória declarativa, que nos interessa especificamente nesse artigo. Uma definição de referência: "A memória declarativa é a memória dos fatos, das idéias e dos eventos, das informações que podem ser conscientemente retomadas sob forma de proposições verbais ou de imagens mentais" (Squire \& Kandel 2002:19-20).

${ }^{18}$ Bulnesia sarmienti, palo santo em espanhol regional.

${ }^{19}$ Devo dizer que sou tomado de forte emoção quando me lembro desses momentos de graça musical, estética e social. Desta feita, a expressão "gravado na memória" assume, mesmo para o estrangeiro, uma força particular.

${ }^{20}$ Por ocasião do meu trabalho de campo, no entanto, eu escutei e registrei uma única vez um garoto, por volta dos 12 anos, cantar em uma sessão em Arocojnadi.

\section{Referências bibliográficas}

AMARILLA STANLEY, Deisy. 2001. Oé Chojinga, relatos bilingües ayoreocastellano. Asuncion: CEADUC.

BADDELEY, Alan. 1993. La mémoire humain. Théorie et pratique. Grenoble: PUG.

BARRIOS, Armindo; BULFE, Domingo \& ZANARDINI, José. 1995. Ecos de la selva, ayoreode uruode. Asunción: Centro de Estudios Antropológicos de la Universidad Católica, Colección Biblioteca Paraguaya de Antropología, v.XXII.

BARTOLOMÉ, Miguel Alberto. 2000. El encuentro de la gente y los insensatos. Mexico y Asunción: Instituto Indigenista Interamericano y CEADUC.
BERNAND-MUÑOZ, Carmen. 1977. Les Ayoré du Chaco septentrional. Etude critique à partir des notes de Lucien Sebag. Paris-La Haye: Mouton.

BÓRMIDA, Marcelo. "Ergon y mito: una hermeneutica de la cultura material de los Ayoreo del Chaco Boreal". Scripta Ethnologica Parte I: 1, pp. 968, 1973 . Parte II: 2(2), pp. 41-107, 1974. Parte III: 3(1), pp. 73-130, 1975. Parte IV: 4(1), p.29-44, 1976. Parte V: 5(1), p.6-25, 1978-79. Parte VI: 5(2), p.21-75, 1978-79.

. e CALIFANO, Mario. 2003 [1978]. "Los Ayoreo del Chaco Boreal". In: J. Zanardini (org.), Cultura del pueblo ayoreo, manual para los 
docentes. Asuncion: CEADUC, Centro Social Indígena, Indianerhilfe in Paraguay e.V. Biblioteca Paraguaya de Antropología v.44, pp. 7-224.

BOWER, Gordon H. 1981. "Mood and memory". American Psychologist, 2:129-148.

BOYER, Pascal. 1988. Barricades mystérieuses et pièges à pensée. Introduction à l'analyse des épopées fang. Paris: Société d'Ethnologie.

BUGOS, Paul. 1985. An evolutionary ecological analysis of the social organization of the Ayoreo of the Northern Gran Chaco. Ph. D. Thesis, Northwestern University.

CASALEGNO, Ugo. 2003 [1985]. “Los relatos/formulas". In: J. Zanardini (org.), Cultura del pueblo ayoreo, manual para los docentes. Asuncion: CEADUC, Centro Social Indígena, Indianerhilfe in Paraguay e.V. Biblioteca Paraguaya de Antropología v.44, pp. 433-488.

CHOME, Ignace. 1958 [por volta de 1745]. "Arte de la lengua zamuca". Journal de la Société des Américanistes, XLVII:123-178.

D'ONOFRIO, Salvatore. 2003. "Guerre et récit chez les indiens Ayorés du Chaco paraguayen". Journal de la Société des Américanistes, 89(1):39-81.

ESTIVAL, Jean-Pierre. 2002. Paraguay: Guarani-Ñandeva et Ayoreo. CD audio. Paris: OCORA Radio France. . 2005. "Introducción a los mundos sonoros ayoreos: referencias, etnografia, textos de cantos". Supplemento Antropológico, XL(1):451502.

FISCHERMANN，Bernd. 1988. Zur Weltsicht der Ayoreode Ostboliviens. Inaugural Dissertation zur Erlangung der Doktorwürde der Philosophischen Fakultät der Rheinischen FriedrichWilhelms-Universität, Bonn.
2005. "La fiesta de la asojna o el cambio de las estaciones entre los Ayoréode del Chaco Boréal". Supplemento Antropológico, XL(1):391450.

KELM, Heinz. 1963. "Die Zamuco. Ostbolivien". Zeitschrift für Ethnographie, 88:66-85.

KEMPER, S.; RASH, S.; KYNETTE, D.; \& NORMAN, S. 1990. "Telling stories: the structure of adults' narratives". European Journal of Cognitive Psychology, 2:205-228.

LUSSAGNET, Suzanne. 1958. "Présentation de 'Arte de la Lengua Zamuca, por el Padre Ignace Chomé'". Journal de la Société des Américanistes, XLVII:121-123.

. 1961. "Vocabulaires samuku, morotoko, poturero et guarañoka, précédés d'une étude historique et géographique sur les anciens Samuku du Chaco bolivien et leurs voisins" (1 ${ }^{a}$. parte). Journal de la Société des Américanistes, L:185-243 .

. 1962. "Vocabulaires samuku, morotoko, poturero et guarañoka" (continuação e fim). Journal de la Société des Américanistes, LI:35-64.

MASHNSHNEK, Celia. 1988-89. "La instrumentación de la ciencia en la economia de los Ayoreo del Chaco boreal". Scripta Ethnologica, XII:43-49.

METRAUX, Alfred. 1996 [1946]. Etnografía del Chaco. Asunción: Editorial El Lector.

PLATEL, Hervé. 2004. Neuropsychologie et neuroanatomie fonctionnelle de la perception musicale. Caen: Institut National de la Santé et de la Recherche Médicale.

PRATT, Michael W. \& ROBINS, S. L. 1991. "That's the way it was: age differences in the structure and quality of adults' personal narratives". Discourse Processes, 14:73-85. 
RENSHAW, John. 1996. Los indígenas del Chaco paraguayo, economia y sociedad. Asuncíon: Intercontinental Editora.

RIESTER, Jürgen \& ZOLEZZI, Graciela. 1985. Cantaré a mi gente. Santa Cruz de la Sierra: Editorial APCOB.

SAMSON, Séverine \& ZATORRE, Robert J. 1991. "Recognition memory for text and melody of songs after unilateral temporal lobe lesion: evidence of dual encoding". Journal of Experimental Psychology, 17:793-804.

SCHMEDA HIRSCHMANN, Guillermo. 2003. "Etnobotanica ayoreo". In: J. Zanardini (org.), Cultura del pueblo ayoreo. Manual para los docentes. Asuncion: CEADUC, Centro Social Indígena, Indianerhilfe in Paraguay e V. Biblioteca Paraguaya de Antropología. v. 44, pp. 505-590.

SEBAG, Lucien. 1965. "Le chamanisme ayoreo". L'Homme, 1:7-32; 2:92-122.

SCHACTER, Daniel L. 1999. A la recherche de la mémoire. Le passé, l'esprit et le cerveau. Paris, Bruxelles: De Boeck Université.

SNYDER, Bob. 2000. Music and memory. An introduction. Cambridge: The MIT Press.

SQUIRE, Larry e KANDEL, Eric. 2002. La mémoire: de l'esprit aux molécules. Paris, Bruxelles: De Boeck Université.

TULVING, Endel e THOMSON, D. M. 1973. "Encoding specificity and retrieval processes in episodic memory". Psychological Review, 80:352-373.

VIVEIROS de CASTRO, Eduardo. 2002. A inconstância da alma selvagem. São Paulo: Cosac \& Naify.

VON BREMEN, Volker. 1991. Zwischen Anpassung und Aneigung Zur Problematik von Wildbeuter-Gesellschaften im modernen Weltsystem am Beispiel der Ayoreode. München: Münchener Amerikanistik Beiträge Nr 26, Anacon Verlag.
ZANARDINI, José (org.). 2003. Cultura del pueblo ayoreo. Manual para los docentes. Asunción: CEADUC, Centro Social Indígena, Indianerhilfe in Paraguay e.V. Biblioteca Paraguaya de Antropología. v. 44. 


\section{Resumo}

Entre os Ayoré do Chaco, um gênero cantado destaca-se dos demais: os irade, cantos narrativos cuja temática está sempre relacionada a um amor frustrado, a feitos guerreiros ou à visão de um xamã. Tais cantos opõem-se às outras formas cantadas ou narradas: a) por sua execução pública investida de uma forte dimensão emotiva, tanto por parte do cantor quanto do público; b) pelo fato de narrar acontecimentos cuja ocorrência deve ser conhecida pelos membros da comunidade; e c) também porque estes cantos estão desprovidos de qualquer dimensão curativa, maléfica ou propiciatória. Uma revisão dos principais resultados das ciências cognitivas, da memória musical e das canções permite-nos mostrar que os Ayoré fizeram uma escolha cultural judiciosa para as condições da performance dos irade: estes últimos são propícios à inscrição mnésica dos cantos entre os sujeitos, constituindo desta forma uma "memória coletiva partilhada" no nível do grupo local.

Palavras-chave: Ayoré, Chaco, Cantos, Memória musical, Ciências cognitivas.

\section{Abstract}

Among the Ayoré of the Chaco, one genre of music is separate from all the rest: irade, narrative songs whose themes always revolve around unrequited love, warrior deeds, or a shaman's vision. These songs are opposed to other sung or narrated forms in the following ways: a) they are publicly executed in an emotional fashion and received in an emotional manner by the public; b) they narrate happenings which are acknowledged by the members of the community as having occurred; and c) they have no curative, propitiating, or cursing dimension. A review of the cognitive sciences, musical memory and the songs in question permits us to see that the Ayoré have made a judicious cultural choice regarding the irade's performance: the conditions under which the songs are sung aid their insertion into the audience's memory, creating in this way a form of "shared collective memory" at the local group level.

Key words: Ayoré, Chaco, Songs, Musical memory, Cognitive sciences. 